\title{
Efficient Generation of Recombinant Adenoviral Vectors by Cre-lox Recombination In Vitro
}

\author{
Kazunori Aoki, ${ }^{1}$ Christopher Barker, ${ }^{1}$ Xavier Danthinne, ${ }^{3}$ \\ Michael J. Imperiale, ${ }^{2}$ and Gary J. Nabel ${ }^{1}$
}

${ }^{1}$ Howard Hughes Medical Institute, University of Michigan Medical Center, Department of Internal Medicine and Biological Chemistry, Ann Arbor, Michigan, U.S.A.

${ }^{2}$ Department of Microbiology and Immunology and Comprehensive Cancer Center, University of Michigan Medical Center, Ann Arbor, Michigan, U.S.A.

${ }^{3}$ Research Service 1 51, VA Medical Center, 500 W. Fort Street, Boise, Idaho, U.S.A.

Communicated by E. Nabel. Accepted March 4, 1999.

\begin{abstract}
Background: Although recombinant adenovirus vectors are attractive for use in gene expression studies and therapeutic applications, the construction of these vectors remains relatively time-consuming. We report here a strategy that simplifies the production of adenoviruses using the Cre-loxP system.

Materials and Methods: Full-length recombinant adenovirus DNA was generated in vitro by Cre-mediated recombination between loxP sites in a linearized shuttle
\end{abstract}

plasmid containing a transgene and adenovirus genomic DNA.

Results: After transfection of Cre-treated DNA into 293 cells, replication-defective viral vectors were rapidly obtained without detectable wild-type virus.

Conclusion: This system facilitates the development of recombinant adenoviral vectors for basic and clinical research.

\section{Introduction}

A major barrier to the application of adenoviral vector technology is the time-consuming procedure of making recombinant viruses. In general, two approaches have been used to generate recombinant adenoviruses. The first is the direct ligation of the adenoviral genome to DNA fragments containing the gene of interest $(1-3)$. Because of the low efficiency of large fragment

Address correspondence and reprint requests to: Dr. Gary J. Nabel, Howard Hughes Medical Institute, University of Michigan Medical Center, Department of Internal Medicine and Biological Chemistry, 1150 West Medical Center Drive, 4520 MSRB I, Ann Arbor, MI 48109-0650, U.S.A. Phone: 734-647-4798; Fax: 734-647-4730; E-mail: gnabel@umich.edu ligations, it is difficult to obtain a sufficient amount of ligated DNA for transfection into helper cells. A second, more widely used method involves homologous recombination in mammalian helper cells between a shuttle plasmid corresponding to the left end of the recombinant and overlapping DNA of virus origin that has been rendered noninfectious (4-6). This approach has facilitated the construction of recombinant adenoviral vectors; however, since homologous recombination is a rare event in mammalian cells, these procedures are often unpredictable, time-consuming, and difficult to control. To circumvent these problems of efficiency and contamination of wild-type adenovi- 
rus, we proposed using Cre-loxP recombination in vitro.

The Cre-loxP recombination system of bacteriophage $\mathrm{Pl}$ catalyzes site-specific recombination in vitro $(7,8)$, in eukaryotic cells $(9-11)$, and in transgenic animals $(12,13)$. Only two components are required to mediate recombination: the 38-kD Cre recombinase and the 34-bp loxP site (14-17). The loxP site consists of two 13-bp inverted repeats flanking an asymmetric 8-bp spacer (15). Cre can mediate inter- or intramolecular recombination upon recognition of two loxP sites on either linear or supercoiled DNA. Recombination between two directly repeated sites on the same DNA molecules excises the DNA segment lying between the sites $(7,18)$. If the loxP sites are present on separate linear molecules, recombinase action results in the mutual exchange of regions distal to the sites $(18,19)$. Using the Cre-loxP reaction, we prepared fulllength recombinant adenoviral DNA in vitro by recombination between a shuttle plasmid and adenovirus genomic DNA that was previously truncated near the left end. Homogeneous viral vectors were effectively obtained 7-9 days after transfecting the recombined DNA into 293 cells. This study shows that recombinant adenoviral DNA can be constructed in vitro using the CreloxP system, which results in highly efficient viral production and decreases the time required to generate adenoviral vectors.

\section{Materials and Methods}

\section{Shuttle Plasmids and Recombinant Adenovirus Cosmid}

In the pAdMCS plasmid, a multiple cloning site

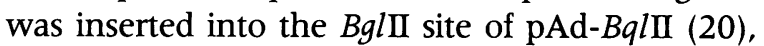
which contains the left-hand sequence of the Ad5 genome, but not ElA and ElB. The pAdMCSloxP plasmid was prepared by introducing a 48-bp oligonucleotide (5'-GCGGCCGCATAACTTCGTATAATGTATGCTATACGAAGTTATAGATCT-3'; the loxP sequence is underlined) into NotI and BglII sites of pAdMCS. The NheI and $\mathrm{XbaI}$ fragment containing the $E$. coli $\beta$-galactosidase gene, under the control of the early enhancer/promoter of cytomegalovirus with an SV40 polyadenylation sequence from pAdCMVlacZ plasmid (20), was inserted into NheI and $X b a I$ sites of pAdMCSloxP to create the pAdCMVlacZloxP plasmid. The lacZ cassette has a nuclear localization signal to direct the $\beta$-galactosidase expression to the nucleus. The Supercos 1 cosmid vector (Stratagene, La Jolla, CA) was used as a backbone to create a recombinant adenoviral cosmid. The 1055-bp fragment of a single loxP sequence and 9.2-12.1 map units $(\mathrm{mu})$ of the Ad5 genome (Lt arm) was amplified by polymerase chain reaction (PCR) from pAdMCSloxP. A $\mathrm{ClaI}$ site was introduced immediately upstream of loxP and a BamHI site was introduced downstream of the $3^{\prime}$ end of the Lt arm with primers Lt/S (5'-AATTATCGATATAACTTCGTATAATTGTATGCTATACGAAG-3') and Lt/AS (5'-AATTGGATCCCCCCTGGCAATCAGCTTGCTACTGAAAGAC- $3^{\prime}$ ). An 853-bp fragment of the right end of the adenovirus genome (Rt arm) was also amplified by PCR from sub360 genomic DNA, an Ad5 derivative with a deletion in the $\mathrm{E} 3$ region, and a BamHI site was introduced upstream of the $5^{\prime}$ end of Rt arm. A ClaI site was introduced downstream of the $3^{\prime}$-ITR with primers Rt/S (5'-AATTGGATCCCTCTCAAACATGTCTGCGGGTTTCTGCATA-3') and Rt/AS (5' -AATTATCGATTTAATTAACATCATCAATAATATACCTTATTTTGGATT- ${ }^{\prime}$ ). To construct Supercos/arms, these two fragments were inserted into the unique ClaI site of the modified Supercos 1 cosmid vector, in which a NotI-NotI fragment was previously deleted to remove the BamHI site. Co-transformation of BamHI-linearized Supercos/arms and sub360 genomic DNA into competent $E$. coli BJ5183 recBC sbcBC bacteria, which has highly efficient homologous recombination machinery (21), regenerated a stable circular cS360loxP cosmid containing a single loxP sequence and 9.2-100 mu of the sub360 genome. ClaI digestion allows the precise excision of the adenoviral genome DNA with a loxP site from cS360loxP. Since DNA yields were low in BJ5183, cS360loxP DNA was retransformed into the DH5 $\alpha$ bacterial strain to isolate large quantities of cosmid DNA.

\section{Cre-Mediated Recombination In Vitro}

Recombination was accomplished in a cell-free reaction mixture consisting of only the viral and plasmid DNAs and Cre recombinase. Equal moles of shuttle plasmid and adenoviral cosmid were recombined in vitro. For example, $5 \mu \mathrm{g}$ of pAdCMVlacZloxP/NheI and $15 \mu \mathrm{g}$ of cS360loxP/ClaI were mixed with $40 \mathrm{U}$ of Cre recombinase (Novagen, Madison, WI) in $600 \mu \mathrm{l}$ of reaction mixture, and incubated at $37^{\circ} \mathrm{C}$ for $3 \mathrm{~h}$. The Cre enzyme was then inactivated at $70^{\circ} \mathrm{C}$ for $5 \mathrm{~min}$. DNA was subsequently purified using a plasmid purification kit (Qiagen Plasmid Midi kits; Qiagen, Santa Clarita, CA), and transfected to 293 cells. 


\section{Cells and Viruses}

The 293 cells were maintained in Dulbecco's modified Eagle medium (DMEM; Gibco-BRL, Gaithersburg, MD) supplemented with $10 \%$ fetal bovine serum (FBS). Smooth muscle cells derived from porcine aorta (PASMC) were maintained in M199 medium (Gibco-BRL) with $10 \%$ FBS. A549 cells were maintained in F-12 medium (Gibco-BRL) with 10\% FBS. To generate infectious recombinant adenoviral vectors, approximately $1 \times 10^{6} 293$ cells were placed in a 6-cm dish $24 \mathrm{hr}$ before transfection, at which time they had reached $80-90 \%$ confluency. Cells were washed once with $3 \mathrm{ml}$ of OptiMEM (Gibco-BRL). Five micrograms of purified Cre recombinase-treated DNA were used for transfection of each $6-\mathrm{cm}$ dish. A transfection mix was prepared by adding $5 \mu \mathrm{g}$ of DNA and $25 \mu \mathrm{l}$ of lipofectAMINE (Gibco-BRL) to $400 \mu \mathrm{l}$ of OptiMEM. After incubation at room temperature for $45 \mathrm{~min}, 1.6 \mathrm{ml}$ of OptiMEM was added to the transfection mix, and the DNA/lipid complex was added to the cells. After $4-5 \mathrm{hr}$ at $37^{\circ} \mathrm{C}$, the transfection mix was removed and $3 \mathrm{ml}$ of growth media were added. Transfected cells were observed daily. After 7 to 9 days, when they showed a cytopathic effect, cells were harvested, then centrifuged at $220 \times g$ for $5 \mathrm{~min}$. The medium was removed and $500 \mu \mathrm{l}$ of $10 \mathrm{mM}$ Tris-Cl, $\mathrm{pH} 8.0$ was added. After four cycles of freezing in ethanol/dry ice and rapid thawing at $37^{\circ} \mathrm{C}$, viral lysate was spun at $2500 \times g$ for $7 \mathrm{~min}$ and adenovirus-containing supernatant was collected. At this point, the viral titers were often high enough to use for gene-transfer experiments in cultured cells. To generate higher titer viral stocks, 293 cells were infected at a multiplicity of infection (MOI) of 0.1 to 1 and grown for 2-3 days, at which time viruses were harvested as described above. This process was repeated 1-2 times, with a final round using $2 \times$ $10^{8}$ cells in fifteen $15-\mathrm{cm}$ dishes. After $2-3$ days, $50 \%$ lysis was observed and the cells were harvested with the resultant viruses purified by $\mathrm{CsCl}$.

\section{Southern Blot Analysis}

Genomic DNA was extracted from 293 cells infected with the crude cell lysate (from day 9), incubated for 3 days, then digested with PmeI, which cuts wild-type and lacZ-adenovirus DNA at one site. One microgram of the digested DNA was fractionated on a $0.4 \%$ agarose gel, transferred onto a nylon membrane, and hybridized with ${ }^{32} \mathrm{P}$-labeled lacZ or El probe in $5 \times$ Denhardt's solution, $0.1 \%$ SDS, $5 \times$ SSPE, and 100 $\mu \mathrm{g} / \mathrm{ml}$ of salmon testis DNA at $65^{\circ} \mathrm{C}$ for $16 \mathrm{~h}$. The filters were then washed in $0.1 \times$ SSC and $0.1 \%$ SDS at $65^{\circ} \mathrm{C}$.

\section{$\beta$-Galactosidase Staining}

$\beta$-galactosidase ( $\beta$-Gal) staining was used to determine the expression of $\beta$-Gal from the recombinant adenovirus. Briefly, the infected cells were fixed for $10 \mathrm{~min}$ at room temperature in phosphate-buffered saline (PBS) buffer with $0.25 \%$ glutaraldehyde. After washing with PBS, the fixed cells were stained using $1 \mathrm{mg} / \mathrm{ml}$ of $\mathrm{X}$-gal (Gibco-BRL) in $5 \mathrm{mM}$ potassium ferricyanide, with $2 \mathrm{mM}$ potassium ferrocynaide and 2 $\mathrm{mM}$ magnesium sulfate.

\section{Results}

Strategy to Make Adenovirus Using Cre-loxP System In Vitro

A shuttle plasmid was constructed that contained the adenoviral 5'-ITR and a packaging signal from 0 to $1 \mathrm{mu}$, the transgene of interest, and a single loxP sequence $3^{\prime}$ of the transgene and 9.2-16.1 mu (Fig. 1A). An adenoviral cosmid was also generated to include $9.2-100 \mathrm{mu}$ of the adenovirus genome, a deletion in the $\mathrm{E} 3$ region and a loxP site at $9.2 \mathrm{mu}$. The shuttle plasmid is linearized at the left end of the viral genome, and the adenoviral cosmid is digested at the left and right end of the viral genome. Cre recombinase produces the full-length recombinant adenoviral vector in vitro by intermolecular recombination between the loxP sites in these two linearized molecules. It is not necessary to remove the unrecombined DNA, because only recombined adenoviral DNA among the four molecules in the Cre reaction mixture can give rise to adenovirus. The Cre-treated DNA is transfected into adenoviral helper cell lines such as 293 cells, and recombinant adenovirus can then be produced.

\section{Recombination Efficiency In Vitro by Cre Recombinase}

The NheI-digested left-end plasmid, pAdCMVlacZloxP, and the ClaI-digested right-end cosmid, cS360loxP, were incubated with Cre recombinase in vitro. To confirm recombination, $500 \mathrm{ng}$ 


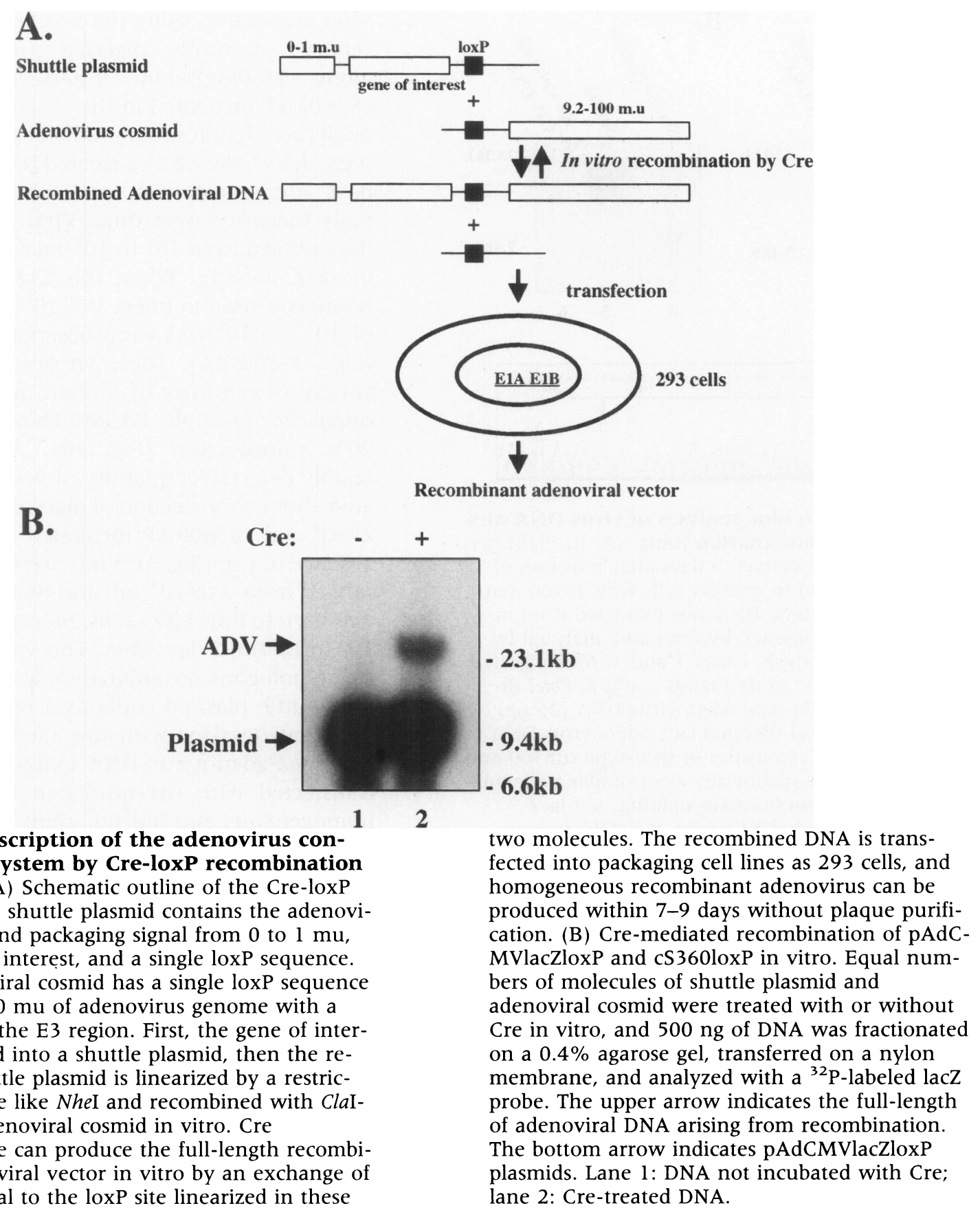

Fig. 1. Description of the adenovirus construction system by Cre-loxP recombination in vitro. (A) Schematic outline of the Cre-loxP system. The shuttle plasmid contains the adenoviral $5^{\prime}$-ITR and packaging signal from 0 to $1 \mathrm{mu}$, the gene of interest, and a single loxP sequence. The adenoviral cosmid has a single loxP sequence and 9.2-100 mu of adenovirus genome with a deletion in the E3 region. First, the gene of interest is cloned into a shuttle plasmid, then the resultant shuttle plasmid is linearized by a restriction enzyme like NheI and recombined with ClaIdigested adenoviral cosmid in vitro. Cre recombinase can produce the full-length recombinant adenoviral vector in vitro by an exchange of regions distal to the loxP site linearized in these of DNA from the reaction was analyzed by Southern blotting with a ${ }^{32} \mathrm{P}$-labeled $\beta$-galactosidase gene (lacZ) probe (Fig. 1B). Full-length recombinant lacZ adenoviral DNA was produced only after incubation with Cre, confirming that the loxP sites in pAdCMVlacZloxP and cS360loxP are functional. The percentage of recombined lacZ-adenoviral DNA was about $1-3 \%$ of that of the pAdCMVlacZloxP plasmid, as determined by densitometry (Fig. 1B, lane 2).

\section{Recombined Adenovirus DNA Is Infectious in 293 Cells}

To produce viruses, Cre-treated DNA ( $5 \mu \mathrm{g}$ ) was transfected into 293 cells. A small number of foci was typically observed 6-7 days later. When lysates were prepared from such foci after 9 days and used to infect fresh 293 cells, a cytopathic effect was observed 2 days later. Genomic DNA was extracted from these secondarily infected 
A.
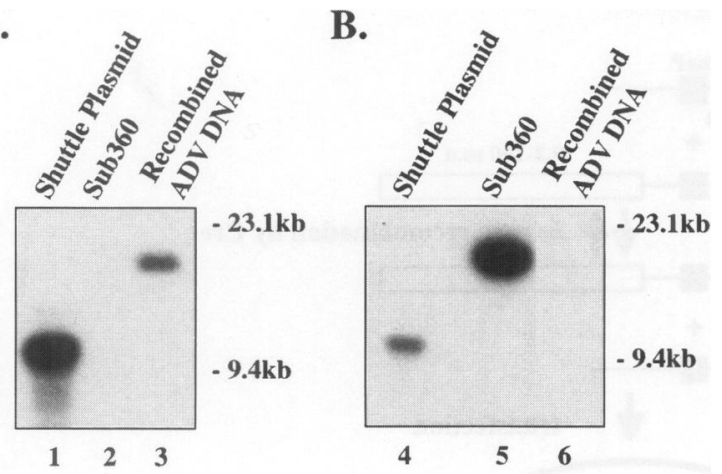

C.

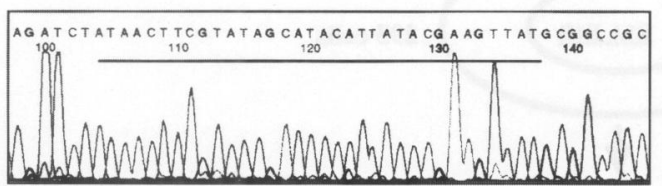

Fig. 2. Southern blot analyses of virus DNA and sequence of recombination joint. (A, B) Eight percent of cell lysate derived 9 days after infection of 293 cells was used to reinfect cells which were harvested after 2-3 days. DNA was extracted from infected 293 cells, digested by PmeI and analyzed by Southern blot analysis. Lanes 1 and 4: NheI-digested pAdCMVlacZloxP (25 ng); lanes 2 and 5: PmeI-digested sub360 wild-type adenovirus DNA (25 ng); lanes 3 and 6: PmeI-digested lacZ-adenovirus DNA ( $1 \mu \mathrm{g}$ ). The band intensities of wild-type sub360 and recombinant lacZ-adenovirus were similar as demonstrated by ethidium bromide staining. (A) lacZ probe; (B) adenoviral El probe. (C) DNA was extracted from CsCl-purified virus, and a recombination joint was sequenced with a primer (5'AAGTGATCGGGCCTCAGCTC- $3^{\prime}$ ) to confirm the precise recombination. The loxP sequence is underlined.

293 cells, digested by PmeI, and the presence of viral DNA confirmed by Southern blot (Fig. 2A). No wild-type adenoviral DNA was detected using an El region as a probe (Fig. 2B, lane 6). Furthermore, no replication-competent virus could be detected after infecting A549 cells with $1 \%$ of the cell lysate for 10 days. These data suggested that in vitro recombination by Cre could give rise to replication-defective infectious adenoviral particles upon transfection of 293 cells with no detectable replication-competent adenovirus. Furthermore, DNA was extracted from CsCl-purified virus, and precise recombination was confirmed by sequencing (Fig. 2C).

\section{Time Course of Viral Production}

To determine the time course of viral production, cells were collected at various times after transfection, and crude cell lysates were assessed for viral production using the $\beta$-galactosidase (lacZ) reporter. Controls, digested pAdCMVlacZloxP alone, cS360loxP alone, or pAdCMVlacZloxP and cS360loxP incubated in the absence of Cre were analyzed. Significant amounts of lacZ adenovirus were detected with Cre-treated DNA as early as 5 days after transfection, and the levels substantially increased over time. Viral titers after 7-9 days ranged from $10^{6}$ to $10^{9} / \mathrm{ml}$ as demonstrated by lacZ staining. When this Cre-treated day 9 lysate was used to infect $1 \times 10^{6} 293$ cells, titers of $10^{10}$ to $10^{11} / \mathrm{ml}$ were observed 2 days later (Figs. 3 and 4A). These viruses could infect a variety of cell lines of human, pig, and mouse origin. For example, PASMC showed more than $90 \%$ transduction (Fig. 4B). A smaller, yet readily detectable, quantity of vector was generated after cotransfection of digested pAdCMVlacZloxP and cS360loxP incubated in vitro in the absence of Cre (Fig. 3). Viral titers after 7-9 days ranged from 0 to $10^{3} / \mathrm{ml}$; and when day 9 lysate was used to infect 293 cells, titers of viruses were $10^{3}$ to $10^{4} / \mathrm{ml} 2$ days later. This virus likely arose by homologous recombination in 293 cells since the shuttle plasmid contains a region, 9.2-16.1 $\mathrm{mu}$, that overlaps with the adenoviral cosmid. This lacZ-adenovirus DNA extracted from cells transfected with Cre-untreated DNA was also homogeneous and did not show any wild-type viral DNA by Southern blot analysis (data not shown). The cells transfected with digested pAdCMVlacZloxP or CS360loxP alone did not give rise to any adenoviral vector foci.

\section{Discussion}

In this report, we describe the use of an in vitro Cre-loxP site-specific recombination system to prepare recombinant adenoviral vectors. The overall strategy involves three steps. First, the gene of interest is cloned into a shuttle plasmid. The plasmid DNA need only contain the $5^{\prime}$-ITR, packaging signal, expression cassette, and a single loxP sequence. The gene of interest can be easily introduced into the shuttle plasmid by standard cloning procedures. Second, the resultant shuttle plasmid is linearized at the left end of the viral genome by a restriction enzyme and recombined in vitro with the ClaI-digested adenoviral cosmid. This second step can be completed in several hours. Third, the recombined DNAs are transfected into helper cell lines such as 293 cells. After 7-10 days, homogeneous viruses are harvested and either used directly for 

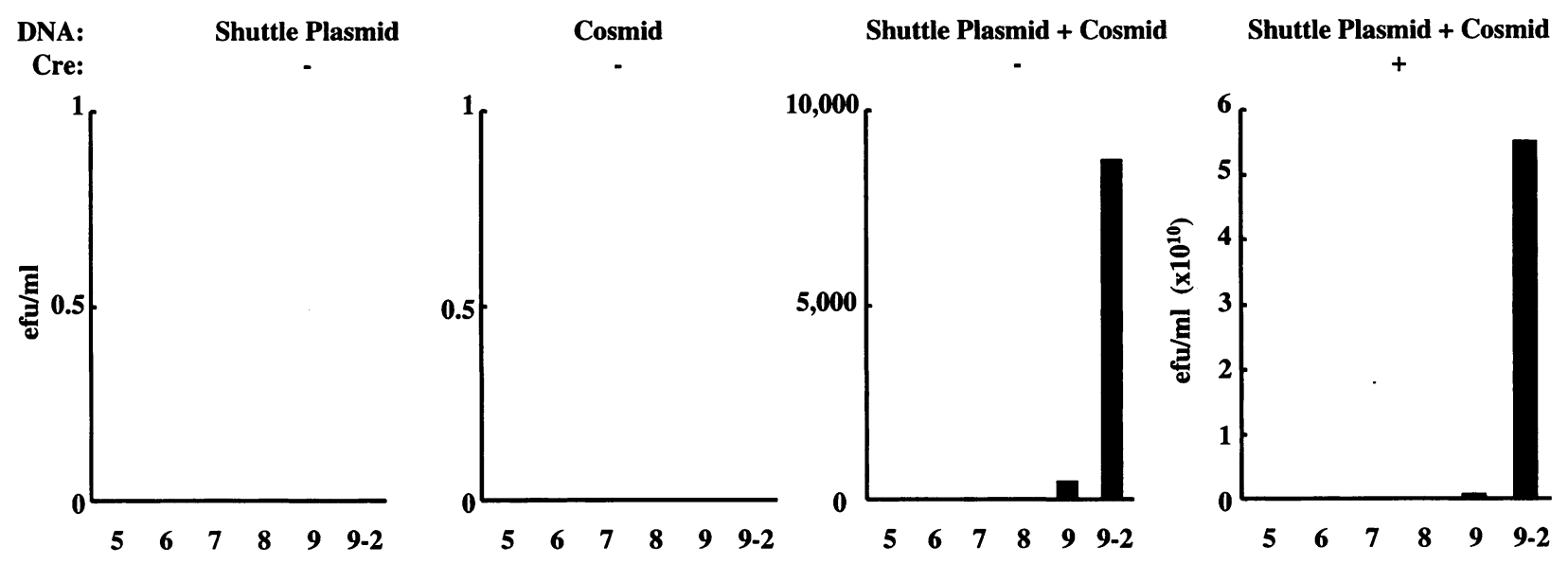

Fig. 3. Production of lacZ adenovirus monitored by $\beta$-galactosidase staining. Cre-treated DNA $(5 \mu \mathrm{g})$ was transfected into 293 cells (with a transfection efficiency of $\sim 30 \%$ by $\beta$-galactosidase staining), and cells were harvested at the indicated times after transfection. Eight percent of the cell ly-

plaque isolation, for experiments, or for further amplification by reinfection of helper cells.

The recombination efficiency observed for this Cre-loxP system was estimated to be $1-3 \%$ when $5 \mu \mathrm{g}$ of Cre-treated DNA was transfected into 293 cells. Therefore, $\sim 100 \mathrm{ng}$ of full-length recombinant adenovirus DNA was estimated to be transfected. Although many 293 cells should have the capacity to produce virus from the transfected vector, only 5-10 adenovirus-producing foci were observed per each dish. The

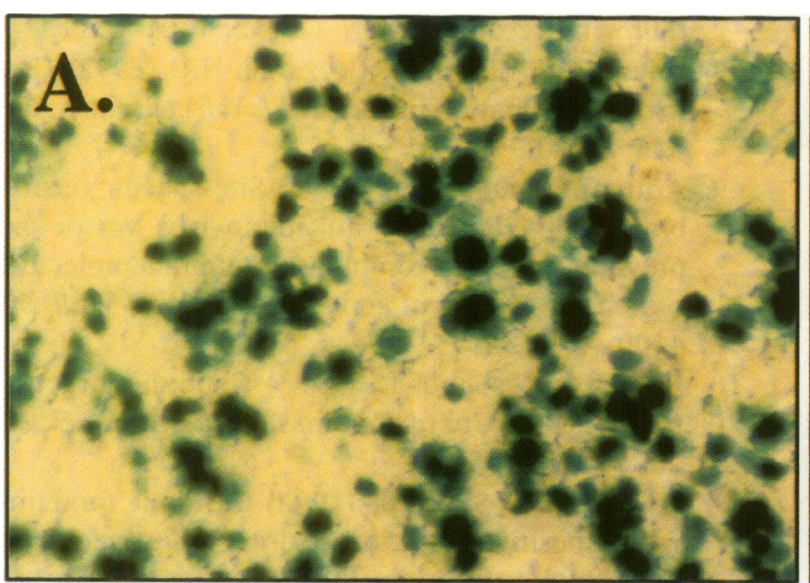

Fig. 4. Expression of $\beta$-galactosidase in 293 and PASMC cells. (A) The 0.08 percent of day 9 cell lysate was used to infect $5 \times 10^{5} 293$ cells, and stained with X-gal at 18-hr postinfection. (B) Eight
Day

sate from day 9 was used to infect $1 \times 10^{6} 293$ cells. Two days later, cell lysates were prepared (day 9-2). The titers of the viruses are presented as lac $Z$ expression forming units (efu)/ml on 293 cells. The efu/ml is equivalent to titers determined by plaque assays.

degradation of endogenous DNA and the fact that the recombined adenoviral genome lacked the $55-\mathrm{kD}$ terminal protein normally linked to the $5^{\prime}$ end in virus-associated DNA may have reduced the number of cells that produce viruses at this step (22); however, since adenovirus can rapidly replicate in helper cell lines, 5-10 adenovirus-producing foci from $100 \mathrm{ng}$ of adenovirus DNA are enough to effectively produce homogeneous viruses.

A major problem with the conventional in

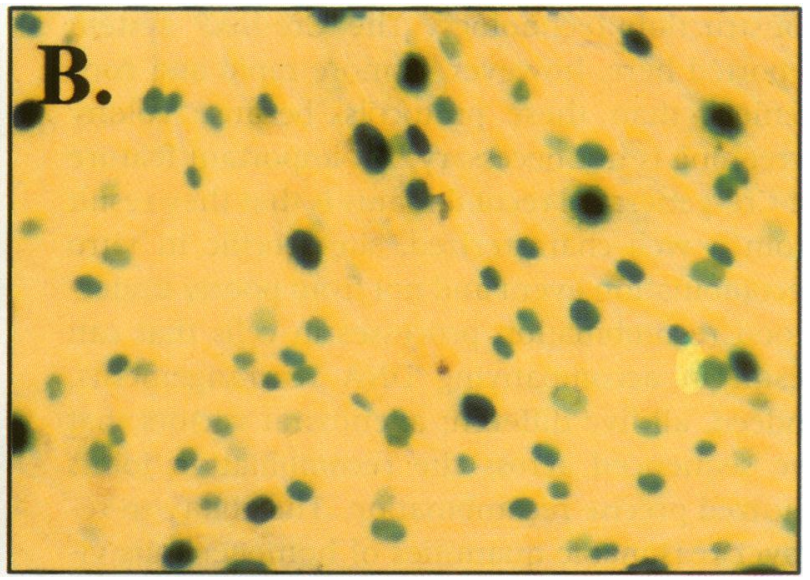

percent of day 9 cell lysate was used to infect $3 \times$ $10^{5}$ PASMC cells, and stained with X-gal at $48-\mathrm{hr}$ postinfection. 
vivo homologous recombination method is the frequent contamination of initial lysates with replication-competent adenoviruses. Our recombinant adenoviral cosmid lacks the adenoviral 5'-ITR and packaging signal, eliminating the possibility of contamination of wild-type adenovirus through incomplete enzyme digestion. The lack of detectable genome heterogeneity in the viral preparation as shown by Southern blot analysis (Fig. 2) indicates that plaque purification is not necessarily required in experiments, and screening of a small number of plaques is enough to identify clones which can be used for further experimental or clinical studies. We have generated more than 15 different adenoviruses with the system described here. Indeed, the different viral preparations were always found to be homogeneous by restriction and Southern blot analysis. Furthermore, we analyzed the contamination of replication-competent viruses in 11 different large-scaled recombinant viruses by TaqMan PCR method (Perkin-Elmer), which is very sensitive and quantitative. Titers of replicationcompetent viruses ranged from 0 to $5 \times 10^{4}$ particle $/ \mathrm{ml}$ in $1 \times 10^{12} \mathrm{particle} / \mathrm{ml}$ of recombinant viruses, which was much less than that of plaque-purified viruses through the conventional in vivo homologous recombination method (data not shown).

There are some reports describing the generation of recombinant viruses through homologous recombination in a yeast or bacteria (2326) or direct ligation using cosmids (27). These methodologies represent a significant improvement over conventional recombinant adenoviral construction technology. The Cre-loxP system reported here, however, is more rapid and convenient than these protocols, because colony screening is not necessary. An important feature of Cre-generated recombinants is that they result from a well-characterized, site-specific in vitro recombination event and not from poorly understood recombination processes in cells that can result in accompanying DNA rearrangements. Indeed, all five different adenoviral vectors that we sequenced across the recombination joints showed precise recombination. The ability to recover reasonable quantities of homogeneous viruses over a short time represents a major practical advantage, and can facilitate the development of adenoviral vectors for a variety of purposes.

\section{Acknowledgments}

We thank Ms. Donna Gschwend for secretarial assistance, Ms. Nancy Barrett for preparation of figures, and Ms. Kay Cherian for her helpful advice and comments. This work was supported in part by a grant from the National Institutes of Health (GM34902).

\section{References}

1. Ballay A, Levrero M, Buendia M, Tiollais P, Perricaudet $M$. (1985) In vitro and in vivo synthesis of the hepatitis $B$ virus surface antigen and of the receptor for polymerized human serum albumin from recombinant human adenoviruses. EMBO $\mathrm{J}$. 4: 3861-3865.

2. Gilardi P, Courtney M, Pavirani A, Perricaudet $M$. (1990) Expression of human $\alpha_{1}$-antitrypsin using a recombinant adenovirus vector. FEBS Lett. 267: 60-62.

3. Rosenfeld MA, Siegfried W, Yoshimura K, et al. (1991) Adenovirus-mediated transfer of a recombinant $\alpha$ l-antitrypsin gene to the lung epithelium in vivo. Science 252: 431-434.

4. McGrory WJ, Bautista DS, Graham FL. (1988) A simple technique for the rescue of early region 1 mutations into infectous human adenovirus type 5. Virology 163: 614-617.

5. Stratford-Perricaudet L, Makeh I, Perricaudet M, Briand P. (1992) Widespread long-term gene transfer to mouse skeletal muscles and heart. J. Clin. Invest. 90: 626-630.

6. Chinnadurai G, Chinnadurai S, Brusca J. (1979) Physical mapping of a large-plaque mutation of adenovirus type 2. J. Virol. 32: 623-628.

7. Abremski K, Hoess R, Sternberg N. (1983) Studies on the properties of $\mathrm{Pl}$ site-specific recombination: evidence for topologically unlinked products following recombination. Cell 32: 1301-1311.

8. Adams DE, Bliska JB, Cozzarelli NR. (1992) Crelox recombination in Escherichia coli cells. Mol. Biol. 226: 661-673.

9. Anton M, Graham FL. (1995) Site-specific recombination mediated by an adenovirus vector expressing the Cre recombinase protein: a molecular switch for control of gene expression. J. Virol. 69: 4600-4606.

10. Baubonis W, Sauer B. (1993) Genomic targeting with purified Cre recombinase. $\mathrm{Nucl}$. Acids Res. 21: 2025-2029.

11. Fukushige S, Sauer B. (1992) Genomic targeting with a positive-selection lox integration vector allows highly reproducible gene expression in mammalian cells. Proc. Natl. Acad. Sci. U.S.A. 89: 7905-7909.

12. Gu H, Zou Y, Rajewsky K. (1993) Independent control of immunoglobulin switch recombination 
at individual switch regions evidenced through cre-loxP-mediated gene targeting. Cell 73: 11551164.

13. Gu H, Marth JD, Orban PC, Mossmann H, Rajewsky K. (1994) Deletion of a DNA polymerase beta gene segment in $\mathrm{T}$ cells using cell type-specific gene targeting. Science 265: 103-106.

14. Russell SJ. (1994) Replicating vectors for gene therapy of cancer: risks, limitations, and prospects. Eur. J. Cancer 30A: 1165-1171.

15. Hoess RH, Abremski K. (1984) Interaction of the bacteriophage $\mathrm{pl}$ recombinase cre with the recombining site loxP. Proc. Natl. Acad. Sci. U.S.A. 81: 1026-1029.

16. Hoess RH, Abremski K. (1985) Mechanism of strand cleavage and exchange in the cre-lox sitespecific recombination system. J. Mol. Biol. 181: 351-362.

17. Hoess RH, Ziese M, Sternberg N. (1982) Pl sitespecific recombination: nucleotide sequence of the recombining sites. Proc. Natl. Acad. Sci. U.S.A. 79: 3398-3402.

18. Kilby N, Snaith M, Murray JAH. (1993) Site-specific recombinases: tools for genome engineering. Trends Genet. 9: 413-421.

19. Simpson P. (1993) Flipping fruit-flies: a powerful new technique for generating Drosophila mosaics. Trends Genet. 9: 227-228.

20. Davidson BL, Allen ED, Kozarsky KF, Wilson JM, Roessler BJ. (1993) A model system for in vivo gene transfer into the central nervous system using an adenoviral vector. Nat. Genet. 3: 219-223.

21. Hanahan D. (1983) Studies on transformation of Escherichia coli with plasmids. J. Mol. Biol. 166: 577-580.

22. Sharp PA, Moore C, Haverty J. (1976) The infectivity of adenovirus 5 DNA-protein complex. $\mathrm{Vi}$ rology 75: 442-456.

23. Ketner G, Spencer F, Tugendreich S, Connelly C, Hieter P. (1994) Efficient manipulation of the human adenovirus genome as an infectious yeast artificial chromosome clone. Proc. Natl. Acad. Sci. U.S.A. 91: 6186-6190.

24. Chartier C, Degryse E, Gantzer M, Dieterle A, Pavirani A, Mehtali M. (1996) Efficient generation of recombinant adenovirus vectors by homologous recombination in Escherichia coli. J. Virol. 70: 4805-4810.

25. Crouzet J, Naudin L, Orsini C, et al. (1997) Recombinational construction in Escherichia coli of infectious adenoviral genomes. Proc. Natl. Acad. Sci. U.S.A. 94: 1414-1419.

26. He T-C, Zhou S, Da Costa LT, Yu J, Kinzler KW, Vogelstein B. (1998) A simplified system for generating recombinant adenoviruses. Proc. Natl. Acad. Sci. U.S.A. 95: 2509-2514.

27. Fu S, Deisseroth AB. (1997) Use of the cosmid adenoviral vector cloning system for the in vitro construction of recombinant adenoviral vectors. Hum. Gene Ther. 8: 1321-1330. 